Gut, 1973, 14, 50-53

\title{
The use of combined ultrasonic and isotope scanning in the diagnosis of amoebic liver disease
}

\author{
A. W. MATthews, K. R. GOUGh, E. RHYS DAVies, F. G. M. ROSS, AND \\ A. HINCHLIFFE
}

From the Royal United Hospital, Bath, and United Bristol Hospitals

SUMMARY The use of combined isotope and ultrasonic scanning in the diagnosis of amoebic liver abscess is described, together with details of three cases of this condition seen in the Bristol area in a period of two years. The addition of ultrasonic scanning greatly increases the accuracy of diagnosis by demonstrating a fluid-filled, space-occupying lesion and should ideally be employed whenever liver abscess is suspected.

Amoebic liver abscess is not common in the British Isles but sporadic cases occur and lack of familiarity with the condition may lead to delay in diagnosis and treatment, possibly with fatal consequences (Wright, 1966). The clinical features have been well described (Lamont and Pooler, 1958), but routine pathological and radiological investigations yield largely non-specific results and may even fail to point to the liver as the site of the disorder.

The proteolytic enzymes of Entamoeba histolytica produce a necrotic, fluid-filled lesion the contents of which are not true pus but liquefied liver cells. Confirmation of the diagnosis depends on aspiration of the typical 'anchovy sauce' fluid and a combination of ultrasonic and isotope scanning offers a safe and rapid means of localizing the lesion and determining its consistency.

\section{Methods}

Localization by conventional radiological methods is not possible because of the absence of specific radiological signs. On the other hand, an abscess, in common with other localized lesions of the liver, will create abnormalities in both the scintigraphic and ultrasonic images. The methods used for both isotope and ultrasonic scanning have been described in detail elsewhere (McCarthy, Davies, Wells, Ross, Follett, Muir, and Read, 1970).

\section{ISOTOPE SCAN}

Serial anterior and lateral scintigrams were done, beginning 15 minutes after the intravenous injection Received for publication 7 November 1972. of $2 \mathrm{mCi}$ Technetium $99 \mathrm{~m}$ sulphide colloid (Patton, Garcia, and Webber, 1966).

\section{ULTRASONIC SCAN}

The subcostal route was used and both $A$ and $B$ scope examinations were performed on each patient (Wells, McCarthy, Ross, and Read, 1969). On the A scan (Fig. 1b) echoes arising at interfaces between tissues of different acoustic properties result in deviations of the baseline proportional to their intensity. The B scan (Fig. 1a) represents a section through the liver with the echoes shown as dots of light. It was found that differentiation of the abscess from the surrounding liver could be enhanced if the swept gain was switched out. This control makes allowance for absorption of sound waves by the tissues which would cause a reduction in intensity of the echoes from the deeper parts of the liver. This was the only variation from the routine scanning methods introduced in these patients.

Both methods are simple and well tolerated. The radiation hazard from serial scintigrams is well within the permitted range (Smith, 1965).

\section{Patients}

CASE 1

C.B., a 27-year-old seaman, was admitted with a three-week history of weight loss, rigors, and rightsided upper abdominal pain. Six weeks previously he had noticed some blood in his stools but no diarrhoea. He had called at Dacca, West Africa, nine months previously.

On examination he was febrile but not jaundiced. 
The liver was slightly enlarged and tender. There were signs of collapse and consolidation in the right lower lobe. Sigmoidoscopy was normal.

Liver function tests showed serum bilirubin 1.4 $\mathrm{mg} / 100 \mathrm{ml}$, alkaline phosphatase $27 \mathrm{~K} \mathrm{Au} / 100 \mathrm{ml}$, SGPT and serum proteins normal. Fresh stool preparations were examined and cysts of E. histolytica were seen. The amoebic fluorescent antibody titre was 1:64 (normal less than 1:32). The serum $B_{12}$ was over $700 \mathrm{pg} / \mathrm{ml}$. High $B_{12}$ levels have been shown to be a feature of amoebic and pyogenic liver abscesses (Neale, Caughey, Mallin, and Booth, 1966).

A scintigram showed a well defined defect high in the right lobe of the liver (Figs. 2a, b) and an

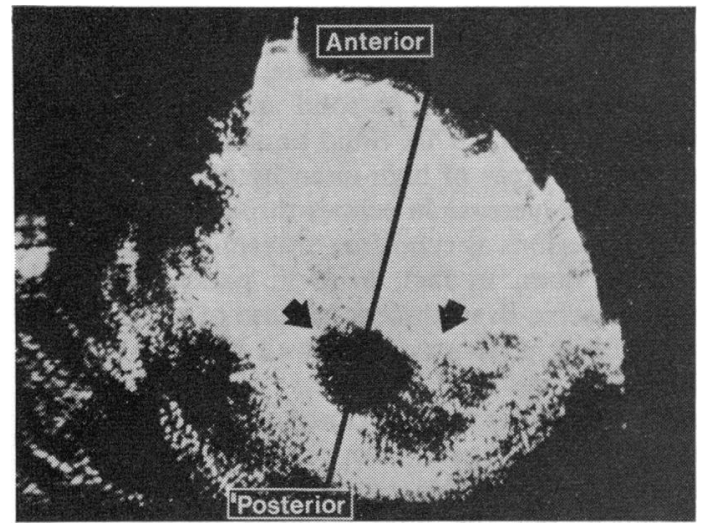

Fig. 1a ultrasonic scan showed one large and several small fluid-filled cavities (Fig. 1a).

A needle was introduced in the position indicated by the scans and a quantity of typical 'anchovy sauce' fluid aspirated. No amoebae were found and it was sterile on culture.

The patient was treated with Metronidazole and made an uninterrupted recovery.

CASE 2

A 54-year-old Nigerian seaman was admitted with a history of mild diarrhoea for two years, and pain in the right lower chest for six weeks.

He was febrile and the liver was slightly enlarged but not tender. There were signs of a small right

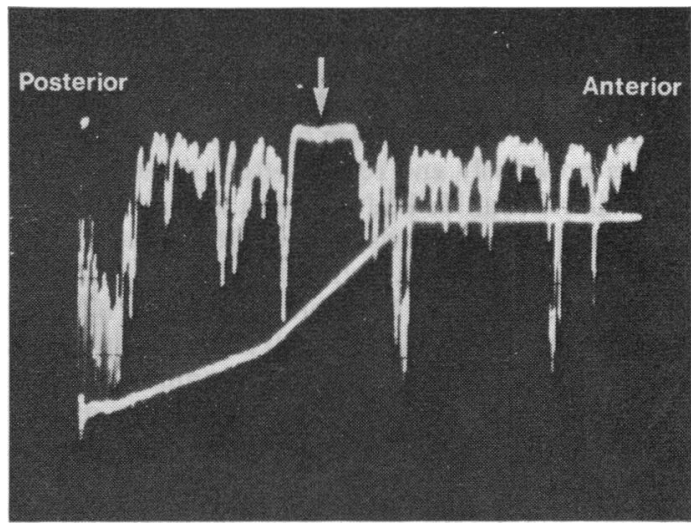

Fig. 1b

Fig. 1a Case 1: ultrasonic B scan, horizontal section showing transonic fluid-filled areas posteriorly (arrowed).

Fig. 1b Ultrasonic A scan along black line marked in Fig. la showing echo-free, transonic area (sloping line is the swept gain function).

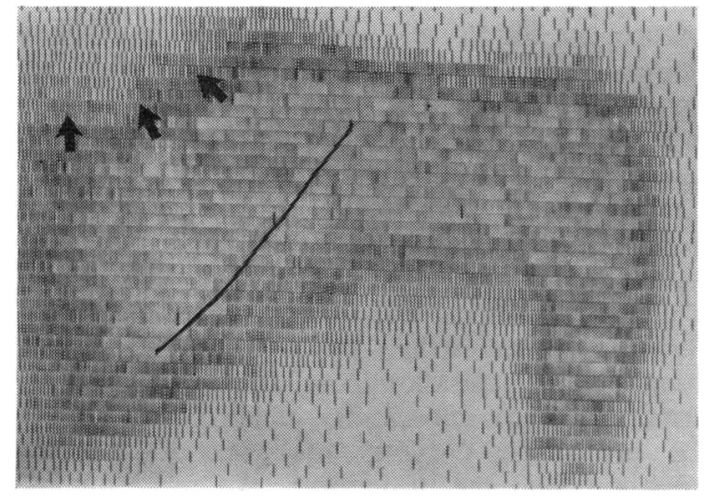

Fig. 2a

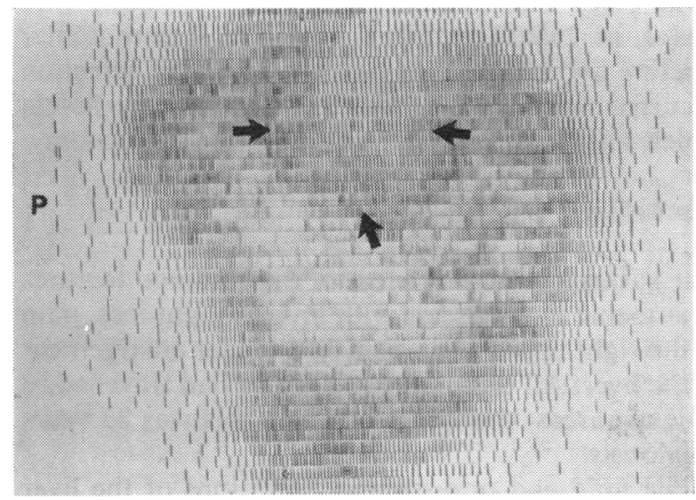

Fig. 2b

Fig. 2a Case 1: antero-posterior scintiscan showing defect high in the right lobe (arrowed), and level of right costal margin.

Fig. 2b Lateral scintiscan showing same defect as in Figure $2 a$. 
pleural effusion and a rub was present. Liver function tests showed serum albumin $3.0 \mathrm{~g} / 100 \mathrm{ml}$, alkaline phosphatase $19.5 \mathrm{~K} \mathrm{Au} / 100 \mathrm{ml}$, bilirubin and SGPT normal. Stool microscopy revealed active E. histolytica.

A scintigram showed multiple defects in the liver and an ultrasonic scan showed these to be fluid filled. Two days later the abscess ruptured into the right pleural cavity and $350 \mathrm{ml}$ of brown fluid was aspirated. This was sterile and no amoebae were found.

The patient was treated with intramuscular emetine and the chest was aspirated a further four times. Subsequently he developed severe congestive heart failure, thought to be due to emetine, but he eventually made a complete recovery.

\section{CASE 3}

L.G., a 43-year-old postman, was admitted with a four weeks' history of fever, weight loss, and pain in the right upper abdomen. He had been in Singapore 23 years previously and remembered one episode of bloody diarrhoea. He had not been abroad since.

On examination he was febrile but not jaundiced. The liver was enlarged and tender. Liver function tests showed a serum bilirubin of $1.2 \mathrm{mg} / 100 \mathrm{ml}$, serum albumin $3.3 \mathrm{~g} / 100 \mathrm{ml}$, alkaline phosphatase $48 \mathrm{KA} \mathrm{u} / 100 \mathrm{ml}$, SGPT $37 \mathrm{IU} / \mathrm{ml}$. Scanning was not performed at this time and laparotomy was undertaken. A large abscess was found in the right lobe of the liver containing a mixture of 'anchovy sauce' fluid and yellow pus. Because of the possibility of pyogenic infection a tube drain was left in the abscess cavity. Culture proved sterile and amoebae were not demonstrated in the fluid or in the faeces. Combined scanning was then performed and showed a scintigraphic defect and a fluid-filled lesion on the ultrasonic scan. The amoebic fluorescent antibody titre was 1 in 256. Treatment was with intramuscular emetine and chloroquin orally. Secondary infection occurred leading to formation of a biliary fistula which finally healed one year after the laparotomy.

\section{Discussion}

Our patients presented most of the common features of amoebic liver abscess with fever, weight loss, pain in the right upper abdomen, and tender enlargement of the liver. All three were males and had travelled to endemic areas, though in one case this was 23 years previously.

The mild and non-specific alterations of the liver function tests are usual and severe abnormalities, particularly a low serum albumin, indicate gross liver destruction and a poor prognosis (Butler and McCarthy, 1969). In two of the patients evidence of bowel infection was found, and in two amoebic antibodies were present in a significant titre.

If the clinical features are suggestive combined liver scanning followed by diagnostic aspiration offer the best means of confirming the diagnosis. In the scintigraphic image there is localized defect, and, as the lesions are usually over $2.5 \mathrm{~cm}$ in diameter (Figs. 2a, b), there is no difficulty in detecting them (Otero, 1967). The use of lateral as well as anterior views increases the accuracy of the method and in a combined series of 152 cases using both projections only one lesion was overlooked (Cuarón, Sepúlveda, and Landa, 1965; Otero, 1967). Despite the high accuracy of scintigraphy in locating defects it does not distinguish a fluid-containing lesion from a solid one such as a tumour. However, ultrasonic scanning, while not so accurate as scintiscanning in detecting a localized lesion within the liver, has a high degree of accuracy in determining whether a lesion, once located, is solid or fluid-containing (McCarthy et al, 1970). Solid tumours usually show as localized areas of high intensity echoes, cirrhosis as a diffuse increase in echoes throughout the liver, and fluid lesions as echo-free 'transonic' areas. Some difficulty does, in fact, arise in patients suffering from amoebic liver abscess because of the lack of a well defined, echo-producing wall between the liver substance and the liquefied abscess contents. Experience shows that this can be overcome by switching out the swept gain. In our case this had the effect of recording multiple echoes from the solid liver substance, but the fluid contents of the abscess remained transonic. The site and size of the abscess were then clearly defined (Fig. 1a). In addition further confirmation could be obtained by directing the A scope through the site of the abscess and recording an echo-free reading as the beam passed through the fluid contents (Fig. 1b).

Once the lesion has been localized, diagnostic aspiration is imperative. Hydatid disease can be excluded in most cases by plain radiographs of the abdomen, the Casoni test, and hydatid CFT. Aspiration of the typical 'anchovy sauce' fluid, which is sterile, makes the essential differentiation from pyogenic liver abscess. In the latter condition surgical drainage offers the only hope of survival and even if this is instituted the mortality remains high (Butler and McCarthy, 1969). In amoebic liver abscess while aspiration possibly aids resolution, formal drainage is unnecessary, and probably unwise. The proteolytic enzymes may encourage sinus formation, and the drain may lead to secondary bacterial infection. These factors were probably responsible for the slow healing in case 3 . An adequate course of chemotherapy with a systemic and bowelactive amoebicide should eradicate the infection 
despite incomplete aspiration of the abscess contents (as in case 1).

After treatment it is important to follow the progress of the lesion. If scanning facilities are not available injection of barium sulphate suspension into the cavity after aspiration has been shown to be safe and reliable (Harding et al, 1970). However, serial scans offer an easier way of showing improvement or deterioration and have the added advantage of being able to detect new lesions.

In our small series only in case 1 was the diagnosis established by combined scanning followed by diagnostic aspiration. In case 2 , the abscess declared itself dramatically by rupturing into the pleural cavity. Case 3 illustrates the difficulties of diagnosis but if scanning had been performed before operation it would have shown the presence of a fluid-filled cavity in the liver

We would like to thank Dr J. Macrae and Professor A. G. Riddell for permission to describe patients admitted under their care.

\section{References}

Butler, T. J., and McCarthy, C. F. (1969). Pyogenic liver abscess. Gut, $10,389-399$.

Cuarón, A., Sepúlveda, B., and Landa, L. (1965). Topographic distribution of amoebic abscesses studied by liver scanning. Int. J. appl. Radiat., 16, 603-609.

Harding, T., Lewis, E. A., and Bohrer, S. P. (1970). Intra-cavity barium sulphate in the assessment of amoebic liver abscess. Clin. Radiol., 21, 68-73.

Lamont, N. McE., and Pooler, N. R. (1958). Hepatic amoebiasis. Quart. J. Med., 27, 389-412.

McCarthy, C. F., Davies, E. R., Wells, P. N. T., Ross, F. G. M., Follett, D. H., Muir, K. M., and Read, A. E. (1970). A comparison of ultrasonic and isotope scanning in the diagnosis of liver disease. Brit. J. Radiol., 43, 100-109.

Neale, G., Caughey, D. E., Mollin, D. L., and Booth, C. C. (1966). Effects of intrahepatic and extrahepatic infection on liver function. Brit. med. J., 1, 382-387.

Otero, E. (1967). Gold-198 liver scanning in hepatic amebic disease. J. nucl. Med., 8, 310-311.

Patton, D. D., Garcia, E. N., and Webber, M. M. (1966). Simplified preparation of Technetium $99 \mathrm{~m}$ sulfide colloid for liver scanning. Amer. J. Roentgenol., 97, 880-885.

Smith, E. M. (1965). Internal dose calculation for $99 \mathrm{~m}$. Tc. J. nucl. Med., 6, 231-251.

Wells, P. N. T., McCarthy, C. F., Ross, F. G. M., and Read, A. E. A (1969). Comparison of 'A' scan and compound 'B' scan ultrasonography in the diagnosis of liver disease. Brit.J. Radiol., 42, 818-823.

Wright, R. (1966). Amoebiasis-a diagnostic problem in Great Britain. Brit. med. J., 1, 957-959. 